\title{
DEVELOPMENT OF FUZZY AHP AND TOPSIS APPROACH FOR MULTI-OBJECTIVE Scheduling Problems in Robotic Flexible Assembly Cells
}

\section{ABD, K.; ABHARY, K. \& MARIAN, R.}

Abstract: In today's industrial world, flexibility is a significant issue, keeping industrial companies on a competitive edge. Flexibility signifies a manufacturing system's ability to respond quickly and effectively to market trends, which have become more dynamic and unpredictable, emphasising the need for increasingly flexible systems. One such system is Robotic Flexible Assembly Cell (RFAC), highly modern system, mainly structured from industrial robots, assembly stations and an automated material handling system. The RFAC always require a sophisticated scheduling approach, not only to prevent collisions between robots but also to guarantee higher system utilisation. Hence, the aim of this paper is to integrate Fuzzy Analytic Hierarchy Process (FAHP) with Fuzzy Technique for Order Preference by Similarity to Ideal Solution (FTOPSIS) to optimise the dynamic scheduling in RFAC under different performance measures. This integration offers significant advantages such as dealing with complex decision problems, and handling any decision problems when the information is uncertain due to vagueness and imprecision. In this integration, the FAHP was applied to determine the relative weights for multi scheduling criteria; and the FTOPSIS was applied for evaluation of each alternative scheduling combination based on its overall performance in order to make a final decision.

Key words: Fuzzy AHP, Fuzzy TOPSIS, Scheduling, Robotics, Assembly cells
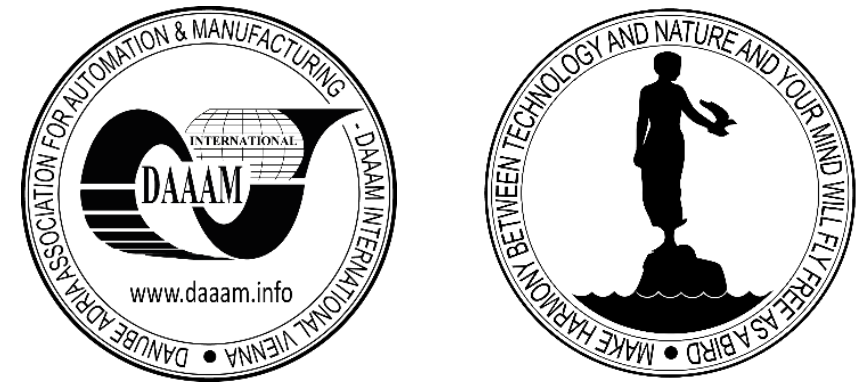

Authors' data: Abd, K[halid]; Abhary, K[azem] \& Marian, R[omeo], University of South Australia, 10 Stuart Road, 5082 Prospect, Australia University of Technology, Baghdad-Iraq, khalid.abd@mymail.unisa.edu.au

This Publication has to be referred as: Abd, K[halid]; Abhary, K[azem] \& Marian, R[omeo] (2017). Development of Fuzzy AHP and TOPSIS Approach for Multiobjective Scheduling Problems in Robotic Flexible Assembly Cells, Chapter 20 in DAAAM International Scientific Book 2017, pp.265-278, B. Katalinic (Ed.), Published by DAAAM International, ISBN 978-3-902734-12-9, ISSN 1726-9687, Vienna, Austria

DOI: $10.2507 /$ daaam.scibook.2017.20 
Abd, K.; Abhary, K. \& Marian, R.: Development of Fuzzy AHP and TOPSIS Appr...

\section{Introduction}

Flexible manufacturing systems have attracted significant attention in recent years due to their flexibility and capacity to deal with unexpected events. One class of such systems is called robotic flexible assembly cells (RFAC) [1-4]. The design of RFAC with more than one robot offers many advantages, e.g. efficiency due to a reduced work environment [5], increased robustness enabling the assembly of a variety of products using the same resources [6], and flexibility due to superior ease of modification and reconfiguring [7]. Accordingly, employing multi-robots in RFAC offers the advantage of increased productivity in a shorter cycle time with lower production costs. Nevertheless, there are certain difficulties that have arisen with this design concept. For example, two robots operating simultaneously in the same work environment require a complex control system to prevent collisions between them [8]. Also, industrial robots must be employed as effectively as possible due to the high cost of the robots. To overcome these difficulties, efficient scheduling of RFAC is required.

Some of the research studies in this field have attempted to solve scheduling problems which have multi-objectives. The methodologies described in these studies have been achieved through simulation or artificial intelligence approaches; however, there is a lack of methodologies for dealing with optimisation problems. This deficiency is due to the weighting method (i.e. assigning weights for each objective) used to transform a multi-objective problem to a single-objective problem and optimise the new single-objective problem e.g. [9-12]. Commonly, the weights are determined by schedulers based on their own judgments of the importance of each objective $[13,14]$. In fact, the weighting method is based purely on subjective assessment by human experts. Consequently, this method still cannot reflect the human thinking process. In order to deal with the subjectivity of human thought, fuzzy set theory can be used. The main feature of fuzzy sets is their ability to mathematically represent vague knowledge [15].

One class of fuzzy set methodologies' Fuzzy Multi-Criteria Decision-Making (Fuzzy MCDM), considers optimisation problems that may have more than one objective function [16]. The objective of this study is to solve multi-objective optimisation problems for scheduling in RFAC, using fuzzy MCDM.

\section{Overview of Multi-Criteria Decision-Making methods}

Multi-criteria decision-making (MCDM) method is extensively used for evaluating a number of feasible solutions against a number of criteria and determining the best solution which meets all the criteria. Selecting a suitable MCDM method is partly based on the decision maker's preference. In recent years, many methods have been proposed for solving MCDM problems. Examples of these methods are WSM (Weighted Sum Model), WPM (Weighted Product Model), AHP (Analytic Hierarchy Process), TOPSIS (Technique for Order Preference by Similarity to Ideal Solution) and SMART (Simple Multi-Attribute Rating Technique) [17]. There is no universally accepted MCDM method, but some methods are more suitable than others for solving 
particular decision problems. AHP and TOPSIS are the most well-known MCDM methods [18].

AHP method was originally developed by Saaty. The AHP method is widely used and can effectively handle both quantitative and qualitative data in different practical decision making problems [19]. This method consists of three main stages: first, constructing a pair-wise comparison matrix; second, synthesising judgments; third, checking for consistency [20,21]. Even though AHP has been successfully applied to solve different decision problems, it has a number of drawbacks. First, this method is still used in nearly crisp decision applications [22]. Second, AHP cannot reflect the human thinking style, due to the fact that it deals with subjective assessments [23]. Third, it does not have the ability to handle decision problems when the information is uncertain and ambiguous [24]. To overcome the above drawbacks, AHP is combined with fuzzy set theory, the so called fuzzy AHP method (FAHP) widely used by researchers

TOPSIS was initially presented by Hwang and Yoon. TOPSIS is one of the most common methods used to solve MCDM problems. The basic idea of TOPSIS is that the selected alternative should be close to the best of ideal solution and farthest from the worst one [25]. The features of this method are that it is easy to use, the process is understandable, and also it is capable of taking into account both quantitative and qualitative criteria [26]. Like AHP, TOPSIS has the same drawback of not being suitable for making decisions when the information is uncertain. Therefore, TOPSIS is combined with fuzzy set theory, the so called fuzzy TOPSIS (FTOPSIS), extensively applied in real case studies to deal with MCDM problems.

Other studies integrated FAHP with TOPSIS or AHP with FTOPSIS for evaluating decision problems under different criteria. In these studies, the AHP/FAHP is used to determine the relative weights of the multiple evaluation criteria, and the TOPSIS/FTOPSIS is used for evaluation of each alternative in order to make a final decision. Although these studies indicated that the integration of FAHP with TOPSIS or AHP with FTOPSIS are suitable approaches for solving different decision problems in engineering and technology, they are unable to fully handle the uncertainty and imprecision in real world problems. Thus, the recent studies have integrated FAHP with FTOPSIS; this combination can adequately handle decision problems containing uncertain and ambiguous information, and can also provide the flexibility needed for the decision maker to understand the decision problem.

Based on the previous overview, it can be stated that the FAHP-FTOPSIS is efficient and modern approaches for solving MCDM problems. However, to the best of the author's knowledge, there is no work published that uses fuzzy MCDM method for optimisation of dynamic scheduling problems. Moreover, there is no documented research in the area of MCDM that indicates the application of both FAHP-FTOPSIS approaches. This paper attempts to develop a new approach based on FAHP-FTOPSIS for solving optimisation problems. The main advantages of the proposed approach are: (1) it can mimic human expert reasoning for optimising the dynamic scheduling in RFAC (2) it can effectively handle the problems when the information is uncertain and ambiguous (3) it is powerful enough to deal with complex decision making problems. 
Abd, K.; Abhary, K. \& Marian, R.: Development of Fuzzy AHP and TOPSIS Appr...

\section{Proposed approach}

In this paper, a comprehensive hybrid fuzzy MCDM is developed using FDSS and FAHP-FTOPSIS. The aim of the proposed approach is to optimise multi-objective dynamic scheduling problems in RFAC. To address the above aim, the fuzzy MCDM approach is divided into three phases: problem description; application of fuzzy MCDM; and analysis of the results, as shown in Figure 1. Each of the phases is described in the following sub-sections.

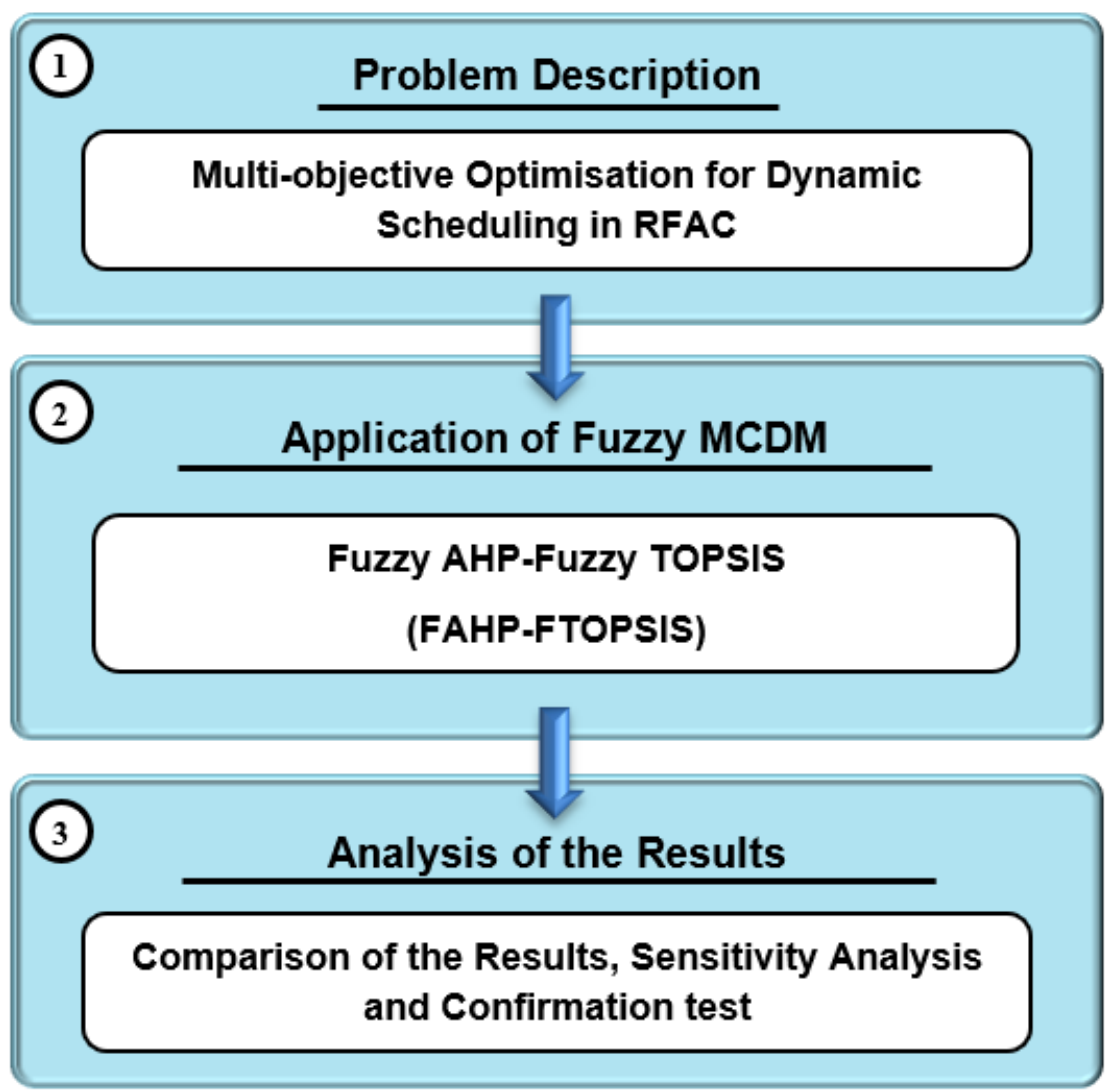

Fig. 1. Simplified flow chart of the developed approach

\subsection{Problem description}

In this phase, the MCDM problem must be described as a hierarchy. The hierarchical structure of the problem can be arranged based on the overall goal, criteria and alternatives [27]. Four steps are required to form the hierarchy of any MCDM problem: (1) define the research problem and identify the overall goal; (2) determine the criteria and sub-criteria that must be used to fulfil the overall goal; (3) identify the decision alternatives; and (4) structure the hierarchy by placing the objective at the top level, the criteria and sub-criteria in the middle and the decision alternatives at the bottom level. The whole hierarchy of the decision making problem can be easily drawn as shown in Figure 2.

Once the hierarchical structure is established, a decision table is built. In this table, the columns indicate the criteria (objective functions), and the rows indicate the alternatives (feasible solutions). The intersections between columns and rows represent the cells. The value in each cell represents the evaluation of the feasible solution with 
respect to the single-objective. The value range for the multi-objective is generally different. To avoid the different ranges, the values in each column must be normalised to values from 0 to 1 . There are two scenarios to perform normalisation: In the first scenario, the objective value is of the smaller the better type. In this case, the normalisation can be determined using Equation 1. In the second scenario, the objective value is of the larger the better type. In this case, the normalisation is determined using Equation 2.

$$
\begin{aligned}
& \mu_{\mathrm{k}}^{\mathrm{i}}=\frac{\left[\eta_{i_{(k)}}-\operatorname{Min} \eta_{i_{(k)}}\right]}{\left[\operatorname{Max}_{i_{(k)}}-\operatorname{Min} \eta_{i_{(k)}}\right]}, \quad 0 \leq \mu_{\mathrm{k}}^{\mathrm{i}} \leq 1 \\
& \mu_{\mathrm{k}}^{\mathrm{i}}=\frac{\left[\operatorname{Max} \eta_{i_{(k)}}-\eta_{i_{(k)}}\right]}{\left[\operatorname{Max} \eta_{i_{(k)}}-\operatorname{Min} \eta_{i_{(k)}}\right]}, \quad 0 \leq \mu_{\mathrm{k}}^{\mathrm{i}} \leq 1
\end{aligned}
$$

where $\mu_{\mathrm{k}}^{\mathrm{i}}$ is the normalised objective value for the $k^{\text {th }}$ response in the $i^{\text {th }}$ feasible solution; $\eta_{i_{(k)}}$ is the value of the objective; Min $\eta_{i_{(k)}}$ and Max $\eta_{i_{(k)}}$ are the smallest and the largest value of $\eta_{i_{(k)}}$ respectively.

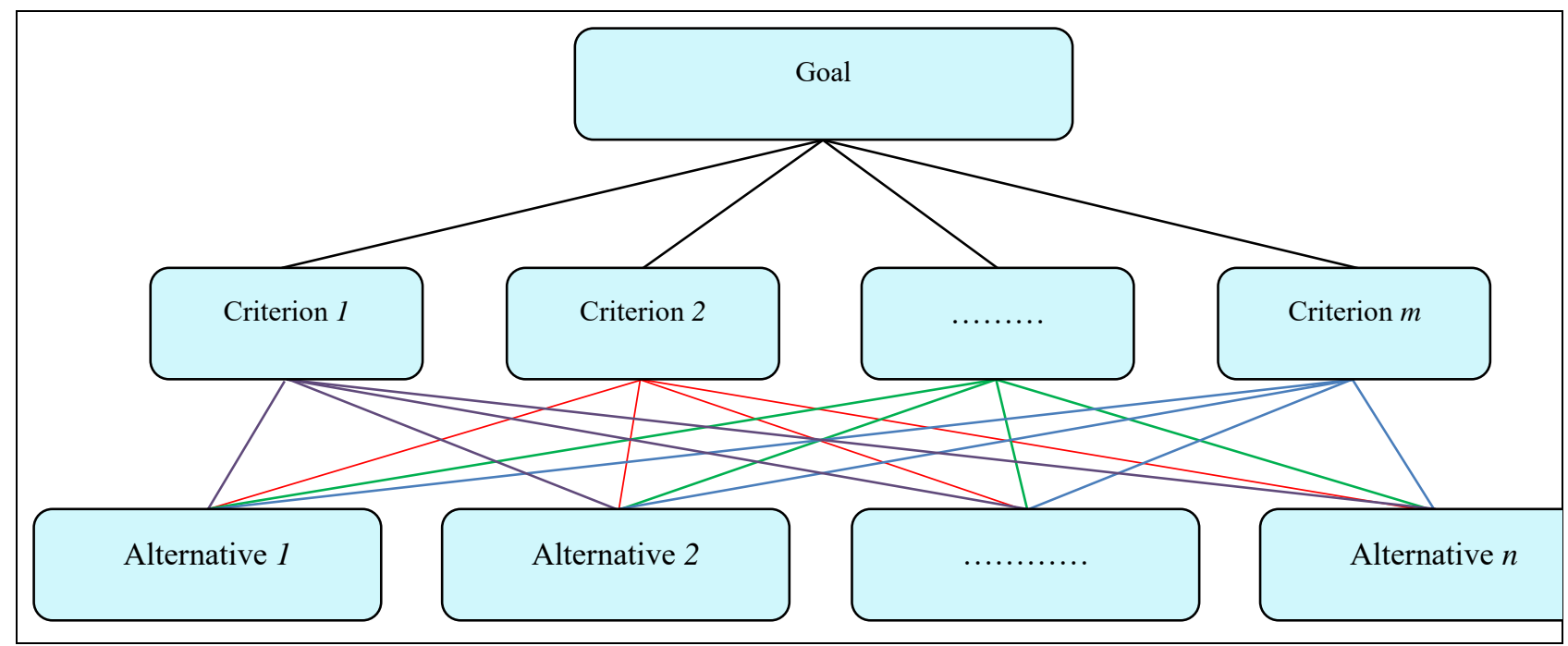

Fig. 2. The hierarchy of the MCDM problem

\subsection{Application of fuzzy MCDM methods}

MCDM methods under the fuzzy environment are applied in order to deal with the vagueness of human thought in making decisions. In this phase, FAHP-FTOPSIS will be used due to their unique characteristics. The approach will be used for two main reasons: firstly, recent studies have showed that the combination of fuzzy AHP method (FAHP) with fuzzy TOPSIS method (FTOPSIS) provides a powerful approach to deal with complex decision problems; secondly, this approach has the ability to handle decision problems when the information is uncertain due to vagueness and imprecision [28]. 
Abd, K.; Abhary, K. \& Marian, R.: Development of Fuzzy AHP and TOPSIS Appr...

In this research, the FAHP is combined with FTOPSIS for optimising the dynamic scheduling in RFAC under different performance measures. The FAHP is applied to determine the weights of the multiple evaluation criteria to be used in the evaluation process; and the FTOPSIS is applied for evaluation of each alternative scheduling combination based on its overall performance in order to make a final decision

\subsection{Analysis of the Results}

In this phase, the outcome results of FDSS and FAHP-FTOPSIS are analysed and discussed. This phase includes checking the stability of the FDSS and FAHP-FTOPSIS results by applying a sensitivity analysis by analyse the obtained results of FMCDM and Fuzzy AHP-Fuzzy TOPSIS. The purpose of this analysis is to investigate the influence of the criteria weights on the final performance ranking, and to check whether a few changes in the criteria weights lead to significant modification in the decision outcome. Therefore, sensitivity analysis provides information on the stability of the results. Based on the previous studies in MCDM, there are two procedures to achieve sensitivity analysis. The first procedure is to increase or decrease the weights of each individual criterion, and keep the summation total of all criteria weights equal to one [29]. The other procedure is to exchange each criterion's weight with another criterion's weight while the other remaining criteria are constant [30].

\section{Implementation of Fuzzy AHP- Fuzzy TOPSIS}

In this section, fuzzy AHP (FAHP) integrated with fuzzy TOPSIS (FTOPSIS) for optimising the dynamic scheduling in RFAC under different performance measures is proposed as a new application. The FAHP is used to determine the relative weight of the multiple evaluation criteria, and the FTOPSIS is applied for evaluation of each alternative in order to make a final decision. The methodology and algorithm steps of FAHP and FTOPSIS are summarised as follows:

\subsection{Methodology of FAHP}

FAHP consists of three main stages: constructing a fuzzy comparison matrix, synthesizing judgments and checking for consistency.

\section{a) Constructing a Fuzzy Comparison Matrix}

The fuzzy matrix $(A)$ of pair-wise comparisons is constructed from $i \times j$ elements, where $i$ and $j$ are the number of criteria (n). Let $A=\left[\tilde{a}_{i j}\right]_{n \times n}$ be a preference matrix such that $\tilde{a}_{i j}=\left(\tilde{a}_{i j}^{l}, \widetilde{a}_{i j}^{m}, \widetilde{a}_{i j}^{n}\right)$ is a triangular fuzzy number (TFN). In this matrix, $\mathrm{a}_{\mathrm{ij}}$ represents the linguistic value of comparing of the $\mathrm{i}$ criterion with respect to the $\mathrm{j}$ criterion, as follows: 


$$
A=\left[\begin{array}{cccc}
\tilde{\mathrm{a}}_{12} & \tilde{\mathrm{a}}_{12} & \cdots & \tilde{\mathrm{a}}_{1 \mathrm{j}} \\
\tilde{\mathrm{a}}_{21} & \tilde{\mathrm{a}}_{22} & \cdots & \tilde{\mathrm{a}}_{2 \mathrm{j}} \\
\vdots & \vdots & \cdots & \vdots \\
\tilde{\mathrm{a}}_{\mathrm{i} 1} & \tilde{\mathrm{a}}_{\mathrm{i} 2} & \cdots & \tilde{\mathrm{a}}_{\mathrm{ij}}
\end{array}\right]
$$

The linguistic value can be determined using TFN. A TFN is denoted as $(1, \mathrm{~m}, \mathrm{n})$, where $1, \mathrm{~m}$ and $\mathrm{n}$ represent, respectively, the smallest value, the most promising value, and the largest possible value of comparing of the $i$ criterion with respect to the $j$ criterion. $\tilde{\mathrm{a}}_{\mathrm{ij}}=\tilde{\mathrm{a}}_{\mathrm{ji}}{ }^{-1}=\left(\mathrm{l}_{\mathrm{ij}}, \mathrm{m}_{\mathrm{ij}}, \mathrm{n}_{\mathrm{ij}}\right)^{-1}=\left(\frac{1}{\mathrm{n}_{\mathrm{ij}}}, \frac{1}{\mathrm{~m}_{\mathrm{ij}}}, \frac{1}{\mathrm{ij}_{\mathrm{ij}}}\right)$, and $\tilde{\mathrm{a}}_{\mathrm{ij}}=(1,1,1)$ when $\mathrm{i}=\mathrm{j}$, as follows:

$$
A=\left[\begin{array}{cccc}
(1,1,1) & \left(l_{12}, m_{12}, n_{12}\right) & \cdots & \left(l_{1 j}, m_{1 j}, n_{1 j}\right) \\
\left(\frac{1}{n_{21}}, \frac{1}{m_{21}}, \frac{1}{l_{21}}\right) & (1,1,1) & \cdots & \left(l_{2 j}, m_{2 j}, n_{2 j}\right) \\
\vdots & \vdots & \cdots & \vdots \\
\left(\frac{1}{n_{i 1}}, \frac{1}{m_{i 1}}, \frac{1}{l_{1}}\right) & \left(\frac{1}{n_{i 2}}, \frac{1}{m_{i 2}}, \frac{1}{l_{i 2}}\right) & \cdots & (1,1,1)
\end{array}\right]
$$

\section{b) Synthesizing Judgments}

This stage represents a process for calculating the weight of each criterion. This process can be achieved as follows:

Step 1: Calculation of fuzzy synthetic extent: The value of fuzzy synthetic extent with respect to the ith is defined as follows:

$$
S_{i}=\sum_{j=1}^{m} \tilde{a}_{i j} \times\left[\sum_{i=1}^{n} \sum_{j=1}^{m} \tilde{a}_{i j}\right]^{-1}
$$

$\sum_{\mathrm{j}=1}^{\mathrm{m}} \tilde{\mathrm{a}}_{\mathrm{ij}}$, is obtained from fuzzy addition operation of $\mathrm{m}$ extent analysis value for a particular matrix such that

$$
\sum_{j=1}^{m} \tilde{a}_{i j}=\sum_{j=1}^{m} l_{j}, \sum_{j=1}^{m} m_{j}, \sum_{j=1}^{m} n_{j}
$$

and $\left[\sum_{\mathrm{i}=1}^{\mathrm{n}} \sum_{\mathrm{j}=1}^{\mathrm{n}} \tilde{\mathrm{a}}_{\mathrm{ij}}\right]^{-1}$ is obtained from fuzzy addition operation of $\tilde{\mathrm{a}}_{\mathrm{ij}}(\mathrm{j}=1,2, \ldots, \mathrm{m})$ values such that

$$
\sum_{i=1}^{n} \sum_{j=1}^{m} \tilde{a}_{i j}=\left(\sum_{i=1}^{n} l_{i j}, \sum_{i=1}^{n} m_{i j}, \sum_{i=1}^{n} n_{i j}\right)
$$


Abd, K.; Abhary, K. \& Marian, R.: Development of Fuzzy AHP and TOPSIS Appr...

Finally, the inverse of the above vector is computed as

$$
\left[\sum_{\mathrm{i}=1}^{\mathrm{n}} \sum_{\mathrm{j}=1}^{\mathrm{m}} \tilde{\mathrm{a}}_{\mathrm{ij}}\right]^{-1}=\left(\frac{1}{\sum_{\mathrm{i}=1}^{\mathrm{n}} \mathrm{n}_{\mathrm{ij}}}, \frac{1}{\sum_{\mathrm{i}=1}^{\mathrm{n}} \mathrm{m}_{\mathrm{ij}}}, \frac{1}{\sum_{\mathrm{i}=1}^{\mathrm{n}} 1_{\mathrm{ij}}}\right)
$$

Step 2: Comparison of fuzzy values: As $\tilde{\mathrm{a}}_{2}$ and $\tilde{\mathrm{a}}_{1}$ are two triangular fuzzy numbers, the degree of possibility of $\widetilde{\mathrm{a}}_{2}=\left(\mathrm{l}_{2}, \mathrm{~m}_{2}, \mathrm{n}_{2}\right) \geq \widetilde{\mathrm{a}}_{1}=\left(\mathrm{l}_{1}, \mathrm{~m}_{1}, \mathrm{n}_{1}\right)$ is defined as

$$
\mathrm{V}\left(\mathrm{a}_{2} \geq \mathrm{a}_{1}\right)=\operatorname{SUP}_{\mathrm{X} \geq \mathrm{Y}}\left[\min \left(\mu_{\mathrm{a}_{1}}(\mathrm{x}), \mu_{\mathrm{a}_{2}}(\mathrm{y})\right)\right]
$$

This is equivalent to

$$
V\left(a_{2} \geq a_{1}\right)=\operatorname{hgt}\left(a_{1} \cap a_{2}\right)=\mu_{a_{2}}(d)
$$

where $d$ is the ordinate of the highest intersection point between $\mu_{a_{1}}$ and $\mu_{a_{2}}$. When $\tilde{\mathrm{a}}_{2}=\left(\mathrm{l}_{2}, \mathrm{~m}_{2}, \mathrm{n}_{2}\right)$ and $\tilde{\mathrm{a}}_{1}=\left(\mathrm{l}_{1}, \mathrm{~m}_{1}, \mathrm{n}_{1}\right)$, then $\mu_{\mathrm{a}_{2}}(\mathrm{~d})$ is defined as follows:

$$
\mu_{\mathrm{a}_{2}}(\mathrm{~d})= \begin{cases}1, & \text { if } \mathrm{m}_{2} \geq \mathrm{m}_{1}, \\ 0, & \text { if } \mathrm{l}_{2} \geq \mathrm{n}_{1}, \\ \left(\mathrm{l}_{1}-\mathrm{n}_{2}\right) /\left[\left(\mathrm{m}_{2}-\mathrm{n}_{2}\right)-\left(\mathrm{m}_{1}-\mathrm{l}_{1}\right)\right], & \text { otherwise }\end{cases}
$$

For the comparison between $\mathrm{a}_{1}$ and $\mathrm{a}_{2}$, the values of both $\mathrm{V}\left(\mathrm{a}_{2} \geq \mathrm{a}_{1}\right)$ and $\mathrm{V}\left(\mathrm{a}_{1} \geq \mathrm{a}_{2}\right)$ are required. The intersection between $\mathrm{a}_{1}$ and $\mathrm{a}_{2}$ is shown in Figure 3.

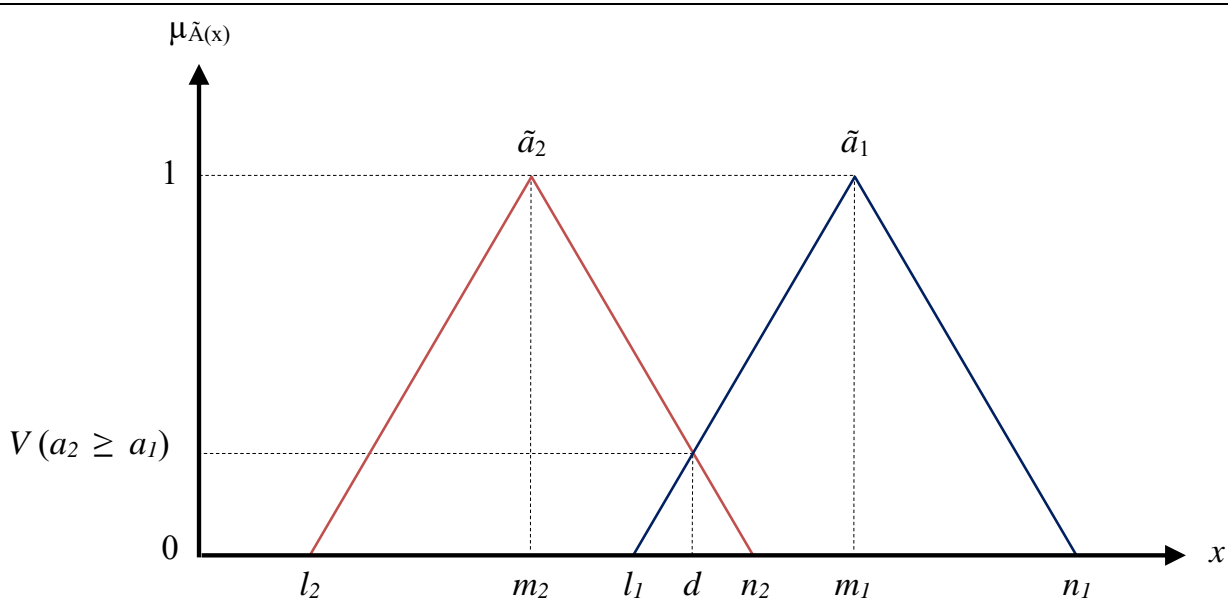

Fig. 3. Interaction between a1 and a2

Step 3: Calculation of priority weights: The degree of possibility for a convex fuzzy number to be greater than $\mathrm{k}$ convex fuzzy numbers $\mathrm{a}_{\mathrm{i}}(\mathrm{i}=1,2, \ldots \mathrm{k})$ can be defined as 


$$
V\left(a \geq a_{1}, a_{1}, \ldots . a_{k}\right)=V\left[\left(a \geq a_{1}\right) \text { and } \ldots \text { and }\left(a \geq a_{k}\right)\right]=\min V\left(a \geq a_{i}\right), \quad i=1,2, \ldots k .
$$

Assuming that

$$
\mathrm{d}^{\prime}\left(\mathrm{C}_{\mathrm{i}}\right)=\min \mathrm{V}\left(\mathrm{S}_{\mathrm{i}} \geq \mathrm{S}_{\mathrm{k}}\right), \mathrm{k}=1,2, \ldots \mathrm{n} ; \mathrm{k} \neq \mathrm{i}
$$

then the weight vector is given by as follow, where $C_{1}, C_{2}, \ldots C_{n}$ are $n$ criteria.

$$
\mathrm{W}^{\prime}=\left\{\mathrm{d}^{\prime}\left(\mathrm{C}_{1}\right), \mathrm{d}^{\prime}\left(\mathrm{C}_{2}\right), \ldots \mathrm{d}^{\prime}\left(\mathrm{C}_{\mathrm{n}}\right)\right\}^{\mathrm{T}}
$$

Step 4: Calculation of normalised weight vectors: The normalised weight vectors are obtained as follows, where $\mathrm{W}$ is a nonfuzzy number

$$
W=\left\{d\left(C_{1}\right), d\left(C_{2}\right), \ldots d\left(C_{n}\right)\right\}^{T}
$$

\section{c) Checking for consistency}

In order to identify the consistency of the linguistic values in the fuzzy matrix (A), the consistency ratio (CR) is calculated. If CR is less than or equal to 0.10 , the linguistic values are acceptable.

If $\mathrm{CR}$ is more than 0.10, the linguistic values are unacceptable and need to be altered. CR can be calculated as follows:

Step 1: Compute the maximum eigenvalue $\left(\lambda_{\max }\right)$ : computed by calculating the consistency value $(\mathrm{CV})$ of each row, then dividing the summation of $\mathrm{CV}$ by $\mathrm{n}$ to obtain $\lambda_{\max }$ as shown in Equation 16.

$$
\lambda_{\max }=\frac{\sum_{\mathrm{i}=1}^{\mathrm{n}} \mathrm{CV}}{\mathrm{n}}
$$

Step 2: Calculate the consistency index (CI), using the following equation.

$$
\mathrm{CI}=\frac{\left(\lambda_{\max }-\mathrm{n}\right)}{(\mathrm{n}-1)}
$$

tep 3: Calculate the consistency ratio (CR): computed by dividing the CI by the random index (RI). The value of RI depends on $\mathrm{n}$. The RI values corresponding with $\mathrm{n}$ are listed in Table 1.

\begin{tabular}{lllcccccc}
\hline Size (n) & $\mathbf{1}$ & $\mathbf{2}$ & $\mathbf{3}$ & $\mathbf{4}$ & $\mathbf{5}$ & $\mathbf{6}$ & $\mathbf{7}$ & $\mathbf{8}$ \\
\hline Random Index (RI) & 0 & 0 & 0.58 & 0.9 & 1.12 & 1.24 & 1.32 & 1.41 \\
\hline
\end{tabular}

Tab. 1. The random consistency index 
Abd, K.; Abhary, K. \& Marian, R.: Development of Fuzzy AHP and TOPSIS Appr...

\subsection{Methodology of FTOPSIS}

FTOPSIS is the algorithm for finding the best option from a set of feasible alternatives. The main stages of FTOPSIS can be described as follows:

\section{a) Establish fuzzy decision matrix}

The first step of the Fuzzy TOPSIS is to construct the $m \times n$ fuzzy-decision matrix ( $\widetilde{D})$.

$$
\begin{aligned}
& \begin{array}{llll}
\mathrm{C}_{1} & \mathrm{C}_{2} & \cdots & \mathrm{C}_{\mathrm{n}}
\end{array} \\
& \widetilde{\mathrm{D}}=\underset{\mathrm{A}_{\mathrm{m}}}{\mathrm{A}_{2}} \underset{\mathrm{A}_{2}}{\vdots}\left[\begin{array}{cccc}
\mathrm{x}_{11} & \mathrm{x}_{12} & \cdots & \mathrm{x}_{1 \mathrm{n}} \\
\mathrm{x}_{21} & \mathrm{x}_{22} & \cdots & \mathrm{x}_{2 \mathrm{n}} \\
\vdots & \vdots & \ddots & \vdots \\
\mathrm{x}_{\mathrm{m} 1} & \mathrm{x}_{\mathrm{m} 2} & \cdots & \mathrm{x}_{\mathrm{mn}}
\end{array}\right]
\end{aligned}
$$

where $i$ is the criterion index $(i=1,2 \ldots m), j$ is the alternative index $(j=1,2 \ldots$ n). $C_{1}, C_{2}, \ldots, C_{n}$ denote the criteria; and $A_{1}, A_{2}, \ldots, A_{m}$ denote the possible alternatives. The elements $x_{i j}=\left(l_{i j}, m_{i j}, n_{i j}\right)$ of the matrix are represented by the linguistic variables for the alternative $\mathrm{j}$ with respect to criterion $\mathrm{i}$.

\section{b) Normalise the fuzzy decision matrix}

The raw data are normalised using linear scale transformation to bring the different measurement units and scales into a comparable scale. The normalised fuzzydecision matrix $\widetilde{\mathrm{R}}$ is calculated as:

$$
\widetilde{R}=\left[\widetilde{r}_{i j}\right]_{m \times n}, i=1,2 \ldots m ; j=1,2, \ldots n
$$

Then the normalisation process, for benefit related criteria (B) and for cost related criteria $(\mathrm{C})$, can be performed using the equations 20 and 21 respectively.

$$
\begin{gathered}
\tilde{r}_{i j}=\left(\frac{l_{i j}}{n_{i j}}, \frac{m_{i j}}{n_{i j}}, \frac{n_{i j}}{n_{i j}}\right), j \in B \\
\tilde{r}_{i j}=\left(\frac{l_{i j}}{l_{i j}}, \frac{m_{i j}}{l_{i j}}, \frac{n_{i j}}{l_{i j}}\right), j \in C
\end{gathered}
$$

\section{c) Compute the weighted decision matrix}

After calculating the weights of the evaluation criteria $\left(w_{j}\right)$ using Fuzzy AHP, the weighted decision matrix $(\widetilde{V})$ can be computed by multiplying the $w_{j}$ with the values of the normalised fuzzy-decision matrix $\left(\widetilde{\mathrm{r}}_{\mathrm{ij}}\right)$. The $\widetilde{\mathrm{V}}$ is defined as 


$$
\widetilde{V}=\left[\tilde{\mathrm{v}}_{\mathrm{ij}}\right]_{\mathrm{m} \times \mathrm{n}}=\left[\tilde{\mathrm{r}}_{\mathrm{ij}} \times \widetilde{\mathrm{w}}_{\mathrm{ij}}\right]_{\mathrm{m} \times \mathrm{n}}, \mathrm{i}=1,2 \ldots \mathrm{m} ; \mathrm{j}=1,2, \ldots \mathrm{n}
$$

\section{d) Determine the positive-ideal solution and negative-ideal solution}

The fuzzy positive ideal solution (FPIS) denoted by $\mathrm{A}^{+}$and the fuzzy negative ideal solution (FNIS) denoted by $\mathrm{A}^{-}$are defined by the equations given below, where $\tilde{\mathrm{v}}_{1}^{+}=(1,1,1)$ and $\tilde{\mathrm{v}}_{1}^{-}=(0,0,0)$ for the benefit criteria, and $\tilde{\mathrm{v}}_{1}^{+}=(0,0,0)$ and $\tilde{\mathrm{v}}_{1}^{-}=$ $(1,1,1)$ for the cost criteria.

$$
\begin{aligned}
& A^{+}=\left\{\tilde{v}_{1}^{+}, \quad \tilde{v}_{2}^{+}, \ldots, \tilde{v}_{j}^{+}\right\}=\left\{\left(\max _{i} v_{\mathrm{v}_{j}} \mid \mathrm{i}=1,2, \ldots, \mathrm{m}\right), \mathrm{j}=1,2, \ldots \mathrm{n}\right\} \\
& \mathrm{A}^{-}=\left\{\tilde{v}_{1}^{-}, \quad \tilde{v}_{2}^{-}, \ldots, \tilde{v}_{j}^{-}\right\}=\left\{\left(\min _{\mathrm{i}} \mathrm{v}_{\mathrm{ij}} \mid \mathrm{i}=1,2, \ldots, \mathrm{m}\right), \mathrm{j}=1,2, \ldots \mathrm{n}\right\}
\end{aligned}
$$

\section{e) Calculate the distance of each alternative}

The distance $\left(\mathrm{d}_{\mathrm{i}}^{+}, \mathrm{d}_{\mathrm{i}}^{-}\right)$of each alternative from $\mathrm{A}^{+}$and $\mathrm{A}^{-}$can be calculated as follows:

$$
\begin{aligned}
& d_{i}^{+}=\sum_{j=1}^{n} d\left(\tilde{v}_{i j}, \tilde{v}_{j}^{+}\right), i=1,2, \ldots m \\
& d_{i}^{-}=\sum_{j=1}^{n} d\left(\tilde{v}_{i j}, \tilde{v}_{j}^{-}\right), i=1,2, \ldots m
\end{aligned}
$$

where $d\left(\tilde{\mathrm{v}}_{\mathrm{ij}}, \tilde{\mathrm{v}}_{\mathrm{j}}^{+}\right)$and $\mathrm{d}\left(\tilde{\mathrm{v}}_{\mathrm{ij}}, \tilde{\mathrm{v}}_{\mathrm{j}}^{-}\right)$denote the distance between two fuzzy numbers as given by the following equations:

$$
\begin{aligned}
& \mathrm{d}\left(\tilde{\mathrm{v}}_{\mathrm{i},}, \tilde{\mathrm{v}}_{\mathrm{j}}^{+}\right)=\sqrt{\frac{1}{3}\left[\left(1-\mathrm{l}_{1}\right)^{2}+\left(1-\mathrm{m}_{1}\right)^{2}+\left(1-\mathrm{n}_{1}\right)^{2}\right]} \\
& \mathrm{d}\left(\tilde{\mathrm{v}}_{\mathrm{i}}, \tilde{\mathrm{v}}_{\mathrm{j}}^{-}\right)=\sqrt{\frac{1}{3}\left[\left(0-\mathrm{l}_{1}\right)^{2}+\left(0-\mathrm{m}_{1}\right)^{2}+\left(0-\mathrm{n}_{1}\right)^{2}\right]}
\end{aligned}
$$

\section{f) Calculate the closeness coefficient}

The relative closeness coefficient $\left(\mathrm{CC}_{\mathrm{j}}\right)$ of each alternative represents the distances to $\mathrm{A}^{+}$and $\mathrm{A}^{-}$simultaneously. The $\mathrm{CC}_{\mathrm{j}}$ can be calculated as follows. The different alternatives can be ranked in descending order according to the value of $\mathrm{CC}_{\mathrm{j}}$. The alternative with highest $\mathrm{CC}_{\mathrm{j}}$ will be the best choice. 
Abd, K.; Abhary, K. \& Marian, R.: Development of Fuzzy AHP and TOPSIS Appr...

$$
\mathrm{CC}_{\mathrm{j}}=\frac{\mathrm{d}_{\mathrm{j}}^{-}}{\mathrm{d}_{\mathrm{j}}^{+}+\mathrm{d}_{\mathrm{j}}^{+}}, \quad \mathrm{j}=1, \ldots, \mathrm{n}
$$

\section{Conclusion}

This paper showed that the integrating of multi-criteria decision-making (MCDM) methodology with fuzzy set theory (fuzzy MCDM) has the ability to: (1) handle any complex problem when the information is uncertain, and (2) reflect the human thinking style. Therefore, a hybrid fuzzy MCDM approach has been developed to achieve multi-objective optimisation of dynamic scheduling in RFAC. The developed approach was divided into three phases: problem description; application of fuzzy methods; and analysis of the results.

In the problem description phase, the steps for converting any MCDM problem to a hierarchical structure were described. This hierarchy is constructed based on three elements: the overall goal, criteria and sub-criteria (objective functions), and the decision alternatives (feasible solutions). The procedure for creating the fuzzy decision matrix is also described in this phase. In the application of the fuzzy MCDM phase, the FAHP and FTOPSIS is integrated, as a new application, to optimise the dynamic scheduling in RFAC under different objective-functions. The FAHP is used to determine relative weights for multi scheduling criteria; and the FTOPSIS is proposed to evaluate the feasible solutions and make a final decision. In the analysis phase, the results of FAHP-FTOPSIS are examined to check whether the proposed are reliable, or not. The proposed approach in this paper will be later applied and validated using a realistic case study as shown in the following paper.

\section{References}

Abd, K, Abhary, K \& Marian, R 2013, 'Intelligent model of scheduling RFACs - Part II: application', DAAAM International Scientific Book Vienna: DAAAM International Publishing, pp. 737-750.

Abd, K, Abhary, K \& Marian, R 2013, 'Intelligent model of scheduling RFACs - Part I: methodology and strategy', DAAAM International Scientific Book Vienna: DAAAM International Publishing, pp. 719-736.

Abd, K, Abhary, K \& Marian, R 2013, 'Development of a fuzzy-simulation model of scheduling robotic flexible assembly cells', Journal of Computer Science, vol. 9, no. 12, pp. 1761-1768.

Abd, K, Abhary, K \& Marian, R 2014, 'Development of an intelligent approach to dynamic scheduling in robotic fleixble assembly cells', IAENG Transaction on Engineering Science, Taylor and Francis Group, London, pp. 203-214.

Mohamed, SB, Petty, DJ, Harrison, DK \& Rigby, R 2001, 'A cell management system to support robotic assembly', The International Journal of Advanced Manufacturing Technology, vol. 18, no. 8, pp. 598-604. 
Marian, RM, Kargas, A, Luong, LHS \& Abhary, K 2003, 'A framework to planning robotic flexible assembly cells', 32nd International Conference on Computers and Industrial Engineering, Limerick, Ireland, pp. 607-615.

Makino, H 1989, 'The comparison between robotic assembly line and robotic assembly cell', Proceedings of the 10th International Conference on Assembly Automation, Canazawa, Japan, pp. 1-10.

Cheng, FSA 2003, 'The simulation approach for designing robotic workcells', Journal of Engineering Technology, vol. 20, no. 2, pp. 42-48.

Adibi, MA, Zandieh, M \& Amiri, M 2010, 'Multi-objective scheduling of dynamic job shop using variable neighborhood search', Expert Systems with Applications, vol. 37, no. 1 , pp. 282-287.

Fattahi, P \& Fallahi, A 2010, 'Dynamic scheduling in flexible job shop systems by considering simultaneously efficiency and stability', CIRP Journal of Manufacturing Science and Technology, vol. 2, no. 2, pp. 114-123.

Tavakkoli-Moghaddam, R, Azarkish, M \& Sadeghnejad-Barkousaraie, A 2011, 'A new hybrid multi-objective Pareto archive PSO algorithm for a bi-objective job shop scheduling problem', Expert Systems with Applications, vol. 38, no. 9, pp. 1081210821.

Zhang, J \& Li, X 2013, Research on dynamic job shop scheduling, Informatics and Management Science V. Springer, London, pp. 43-50.

Rangsaritratsamee, R, Ferrell Jr, WG \& Kurz, MB 2004, 'Dynamic rescheduling that simultaneously considers efficiency and stability', Computers \& Industrial Engineering, vol. 46, no. 1, pp. 1-15.

Xing, LN, Chen, YW \& Yang, KW 2009, 'An efficient search method for multiobjective flexible job shop scheduling problems', Journal of Intelligent Manufacturing, vol. 20, no. 3, pp. 283-293.

Beskese, A, Kahraman, C \& Irani, Z 2004, 'Quantification of flexibility in advanced manufacturing systems using fuzzy concept', International Journal of Production Economics, vol. 89, no. 1, pp. 45-56.

Kahraman, C, Beskese, A \& Kaya, I 2010 'Selection among ERP outsourcing alternatives using a fuzzy multi-criteria decision making methodology', International Journal of Production Research, vol. 48, no. 2, pp. 547-566.

Guarnieri, P 2014, 'Decision making regarding information sharing in collaborative relationships under an MCDA perspective', International Journal of Management and Decision Making, vol. 13, no. 1, pp. 77-98.

Samvedi, A, Jain, V \& Chan, FTS 2013, 'Quantifying risks in a supply chain through integration of fuzzy AHP and fuzzy TOPSIS', International Journal of Production Research, vol. 51, no. 8, pp. 2433-2442.

Javanbarg, MB, Scawthorn, C, Kiyono, J \& Shahbodaghkhan, B 2012, 'Fuzzy AHPbased multicriteria decision making systems using particle swarm optimization', Expert Systems with Applications, vol, 39, no. 1, pp, 960-966. 
Abd, K.; Abhary, K. \& Marian, R.: Development of Fuzzy AHP and TOPSIS Appr...

Vaidya, OS \& Kumar, S 2006, 'Analytic hierarchy process: An overview of applications', European Journal of Operational Research, vol. 169, no. 1, pp. 1-29.

Abd, K, Abhary, K \& Marian, R 2011, 'An MCDM approach to selection scheduling rule in robotic flexible assembly cells', World Academy of Science, Engineering and Technology, vol. 76, no. 1, pp. 643-648.

Patil, SK \& Kant, R 2014, 'A fuzzy AHP-TOPSIS framework for ranking the solutions of Knowledge Management adoption in Supply Chain to overcome its barriers', Expert Systems with Applications, vol. 41, no. 2, pp. 679-693.

Wang, YM, Luo, Y \& Hua, Z 2008, 'On the extent analysis method for fuzzy AHP and its applications', European Journal of Operational Research, vol. 186, no. 12, pp. 735747.

Torfi, F, Farahani, RZ \& Rezapour, S 2010, 'Fuzzy AHP to determine the relative weights of evaluation criteria and Fuzzy TOPSIS to rank the alternatives', Applied Soft Computing, vol. 10, no. 2, pp.520-528.

Shyjith, K, Ilangkumaran, M \& Kumanan, S 2008, 'Multi-criteria decision-making approach to evaluate optimum maintenance strategy in textile industry', Journal of Quality in Maintenance Engineering, vol. 14, no. 4, pp. 375-386.

Ekmekçioğlu, M, Kaya, T \& Kahraman, C 2010, 'Fuzzy multicriteria disposal method and site selection for municipal solid waste', Waste Management, vol. 30, no. 8, pp. 1729-1736.

Triantaphyllou, E 2000, Multi-criteria decision making methods: a comparative study, Kluwer Academic Publishers, Dordrecht.

Patil, SK \& Kant, R 2014, 'A fuzzy AHP-TOPSIS framework for ranking the solutions of Knowledge Management adoption in Supply Chain to overcome its barriers', Expert Systems with Applications, vol. 41, no. 2, pp. 679-693.

Kutlu, AC \& Ekmekcioglu, M 2012, 'Fuzzy failure modes and effects analysis by using fuzzy TOPSIS-based fuzzy AHP', Expert Systems with Applications, vol. 39, no. 1, pp. 61-67.

Mentes, A \& Helvacioglu, IH 2012, 'Fuzzy decision support system for spread mooring system selection', Expert Systems with Applications, vol. 39, no. 3, pp. 32833297. 